\title{
Problems of The
}

\section{East German}

\section{Steel Industry}

If there ever was a region that was not destined to have a steel industry, it is probably that area now included within the borders of Eastern Germany. The ore resources are meager and only of low grade. Likewise, the quality of coal for coking purposes is poor and in limited supply. Before World War II, there was a small steel industry based on scrap arisings in the Berlin region; one small integrated plant, Maxhutte; and a low-shaft blast-furnace plant at Calbe.

But in recent years, East German authorities have been determined to change all of this. Ore would be brought from the Ukraine and coal or coke from Poland to meet on the Oder river where a new integrated plant would be built-Eisenhuttenkombinat Ost (formerly Stalinstadt). Other plants (most of them dismantled at that time) would rise and be expanded into an industrial base for the country. A recent report published by Handelsblatt of Dusseldorf and translated and summarized by the British Iron and Steel Federation gives some insight into the fulfillment of these plans:

Labor productivity in the iron and steel industry of Eastern Germany shows only a slight improvement, despite the efforts of the East German authorities in the last few years. From 1957 to 1960 total production of the steel industry increased about 20 pct with an increase in the labor force of 6 pct. This compares with a 40 pct increase in total production in Western Germany and an increase in the labor force of 18 pct. Nevertheless, pig iron production per production worker in Eastern Germany is only 15 pct of that in Western Germany.

Structural difficulties are the main cause of this relative failure. Plants are badly located, of uneconomic size, not integrated, and lack the opportunity of re-equipping themselves. While it is true that, in the post-war years, the East German steel industry embarked on a program of marked expansion, most of the plants are still small or medium sized.

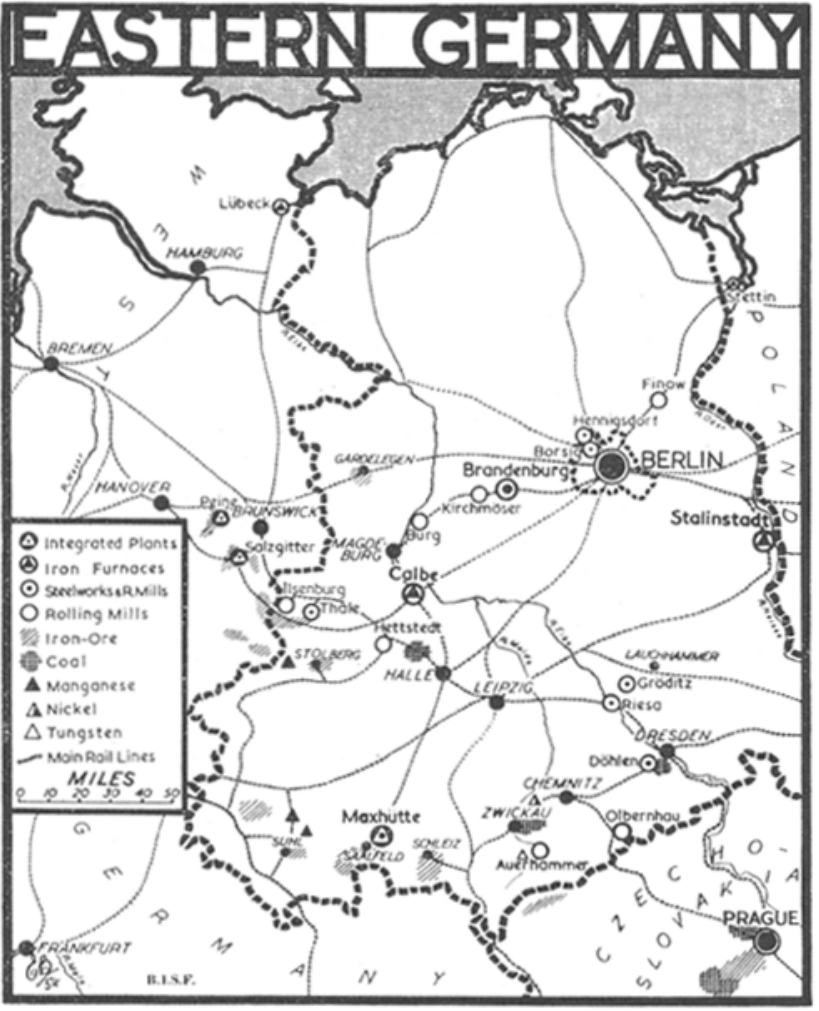

Map courtesy British Iron \& Steel Federation

The German Institute for Economic Research, Berlin, has shown in a recent study that not one fully integrated plant (i.e. coke ovens, blast furnaces, steel plant, and rolling mills) has been built in Eastern Germany. Eisenhuttenkombinat Ost on the Oder river is planned to contain blast furnaces, steel plant, and rolling mills, but at present it produces only pig iron-about $1.2 \mathrm{mil}-$ lion metric tons annually from six medium-sized blast furnaces. The Calbe plant produces only pig and foundry iron. A further large plant, Stahl und Walzwerk Brandenburg, has a steel plant of 11 open-hearth furnaces producing 1.1 million metric tons of steel, plus rolling mills. In a total of 13 steel works in Eastern Germany, six are finishing works, possessing rolling mills, but there is no steel plant.

Further difficulties arise from the disproportion in capacities of various sections within the existing plants. This leads to high fuel costs and increased transport costs due to the large interchange of raw materials and semi-finished products. For example, 40 pet of all ingot steel and semi-finished products must be transported between plants for finishing.

In both Eisenhuttenkombinat Ost and Maxhutte, the coke rate per metric ton of pig iron is $1300 \mathrm{~kg}$ per metric ton hot metal as compared with $826 \mathrm{~kg}$ in Western Germany. This is due, generally, to the insufficiency of sinter plants and ore preparation as well as the poor quality local ore, which is enriched by Krivoi Rog ore with a 50 pct $\mathrm{Fe}$ content but also containing a high share of fines. The mixture of Soviet and Polish coal, which deteriorates due to lengthy transportation, is a contributory factor to poor production. The coke rate at the Calbe works, using lignite high-temperature coke in low-shaft furnaces, is particularly high-2000 kg per metric ton of pig iron-and is costly despite the initial low cost of lignite.

Increased costs also resulted from the Soviet demands that the works previously dismantled for reparations be rebuilt in the old locations, with all the attendant internal transport difficulties. Furthermore, only four or five small modern rolling mills have been built. Most of the rolling mills that have been reerected are old mills previously sent to Russia as reparations and later brought back by the East German authorities. Some of the rolling mills were previously designed for nonferrous products and have-been converted into steel rolling mills. A thorough program of mechanization and automation has been held back by the limited availability of capital. Specialization and mass production are also retarded by the varied demands for special products made on the steel industry by the steel-using industries.

Thus, it appears to us that the picture for the East German steel industry isn't particularly bright. Despite the effort that has obviously been put into it, the fundamental lack of raw materials and a heavyindustry base, would seem to preclude the establishment of a strong steel industry in the small region that is now known as Eastern Germany.

FWs 